\title{
Analisis Wawasan Penjualan Supermarket dengan Data Science
}

\author{
Mawaddah Harahap ${ }^{1 *}$, Facrul Rozi ${ }^{2}$, Yennimar ${ }^{3}$, Saut Dohot Siregar ${ }^{4}$ \\ 1,3,4 Universitas Prima Indonesia, Fakultas Teknologi dan Ilmu Komputer, Teknik Informatika, Indonesia \\ ${ }^{2}$ Universitas Harapan Medan, Fakultas Teknik dan Komputer, Sistem Informasi, Indonesia \\ ${ }^{1}$ mawaddah@unprimdn.ac.id
}

Received: $x x$ xx xxxx

Accepted:

Published:

OPEN ACCESS
*Mawaddah Harahap
Keywords: Data Science,
Supermarket, Analisis
Pelanggan, Analisis Penjualan
DSI: Jurnal Data Science
Indonesia is licensed under a
Creative Commons
Attribution-NonCommercial
4.0 International (CC BY-NC
4.0).

\section{PENDAHULUAN}

Data science atau ilmu data adalah suatu disiplin ilmu yang khusus mempelajari data, khususnya data kuantitatif (data numerik), baik yang terstruktur maupun tidak terstruktur (Dhar 2013). Bidang ilmu data telah muncul dalam menanggapi peningkatan jumlah data. Sejumlah besar data telah tersedia untuk orang-orang di semua lapisan masyarakat, melalui jejaring sosial, perangkat seluler, dan berbagai perangkat sensor (yaitu "InternetofThings") (Virkus and Garoufallou 2019). Salah satu transaksi data yang terus meningkat adalah transaksi penjualan retail seperti supermatrket. Optimalisasi pembelian pelanggan adalah masalah umum bagi banyak perusahaan, baik besar maupun kecil. Untungnya sebagian besar perusahaan harus memiliki banyak data yang tersedia untuk memprediksi kemungkinan perilaku pembelian bagi banyak pelanggan sehingga dapat membuat keputusan yang tepat tentang menyimpan rak, memberikan rekomendasi pelanggan tentang barang, promosi, memprediksi kapan pelanggan kehilangan minat pada layanan dan kapan pelanggan berencana untuk membeli dari pesaing (Salehinejad and Rahnamayan 2017). Mengelola hubungan pelanggan yang baik dalam suatu organisasi mengacu pada konsep, alat, dan strategi manajemen hubungan pelanggan (Anshari et al. 2019) dan umumnya menggunakan analisis data.

Analisis data melibatkan analisis kumpulan data untuk mengungkap tren dan wawasan yang kemudian digunakan untuk membuat keputusan organisasi yang terinformasi (Bashir, Mehboob, and Bhatti 2015). Analisis bisnis difokuskan pada menganalisis berbagai jenis informasi untuk membuat keputusan bisnis yang praktis dan berbasis data, dan menerapkan perubahan berdasarkan keputusan tersebut (Peng et al. 2015). Analisis bisnis sering menggunakan wawasan yang diambil dari analisis data untuk mengidentifikasi masalah dan menemukan solusi (Volk et al. 2017). Setiap keputusan pembelian, email yang diabaikan, penawaran yang diterima, keranjang yang ditinggalkan, ulasan produk, atau tindakan penipuan merupakan bagian integral dari pengalaman sebagian besar perusahaan yang dapat digunakan untuk meningkatkan keputusan bisnis di masa depan (Lieder, Asif, and Rashid 2020), namun bagaimana menghasilkan wawasan yang dapat ditindaklanjuti data perusahaan sehingga menghasilkan informasi yang bermanfaat adalah sebuah pertanyaan yang perlu 
dijawab.

Makalah ini menyajikan analisis wawasan penjualan pada supermarket dengan pendekatan data science dimana pendekatan yang digunakan adalah mengajukan beberapa pertanyaan dan mencoba mendapatkan jawaban tersebut dari data sehingga konstribusi utama penelitian ini adalah menemukan beberapa wawasan yang dapat membantu perusahaan meningkatkan strategi penjualan dan pemasaran di masa depan.

\section{TINJAUAN LITERATUR}

Perilaku pelanggan adalah area penelitian yang dipelajari dengan baik dalam pemasaran ritel dan pengambilan keputusan ritel. Faktor yang berbeda dari sifat manusia dan sosiologi mempengaruhi perilaku pembelian pelanggan (Rahim et al. 2021). Studi perilaku pelanggan dalam belanja online biasanya berkaitan dengan identifikasi pelanggan dan pola perilaku pembelian mereka, beberapa pekerjaan mengusulkan penerapan data mining untuk memahami bagaimana menemukan wawasan yang berguna dalam pengambilan keputusan khususnya dalam bidang retail, seperti (Gull and Pervaiz 2018) menerapkan teknik data mining untuk menganalisis perilaku orang-orang yang mengunjungi situs belanja online dan menghabiskan waktu mereka di sana, menjelajahi berbagai hal. Juga akan diperhitungkan berapa banyak orang yang ada di sana dan berapa banyak dari mereka yang benar-benar berbelanja.

Abirami dan Pattabiraman (Vijayakumar and Neelanarayanan 2016) melakukan klasifikasi pelanggan menggunakan analisis RFM dan menerapkan pendekatan menggunakan korelasi rule mining dan Kmeans. Mereka menggunakan data pelanggan untuk menentukan peringkat pelanggan berdasarkan profitabilitas. Klasifikasi pelanggan potensial di berbagai area produk toko ditunjukkan dalam (Jha et al. 2014), menggunakan Naive Bayesian Classifier dan menggunakan banyak fitur, termasuk fitur RFM, untuk membuat pemasar ritel menguntungkan. bawah pemasar ritel. Kampanye, pemasaran yang menargetkan pelanggan yang sangat menguntungkan.

Metode pengelompokan pelanggan diterapkan dalam (Maheswari, Packia, and Priya 2017) menerapkan klasifikasi Support Vector Machine. Kumpulan data persediaan dan kumpulan data penjualan yang tersedia di internet digunakan, dimana setiap aktivitas pelanggan disimpan sebagai byte data dalam database untuk mengumpulkan informasi seperti bagaimana pelanggan menghabiskan waktu mereka yang berharga, hari dalam keputusan pembelian. Barang yang paling sering dibeli dan jumlah pembelian juga dipertimbangkan. Pemodelan marketing mix disajikan oleh (Istiqomatin, Setiadi, and Ekowati 2021) mengidentifikasi bauran pemasaran terhadap keputusan pembelian untuk membeli pisang cavendish dan menganalisis pengaruh bauran pemasaran terhadap keputusan pembelian untuk membeli pisang cavendish di pasar modern di Semarang dan (Rita, Oliveira, and Farisa 2019) mengembangkan pengetahuan baru untuk lebih memahami dimensi terpenting dari kualitas layanan elektronik yang berdampak pada kepuasan pelanggan, kepercayaan pelanggan, dan perilaku pelanggan, membangun literatur yang ada tentang kualitas layanan elektronik dalam belanja online.

\section{BAHAN DAN METODE}

Bahan dan metodologi yang digunakan pada penelitian ini diuraikan sebagai berikut:

\section{Pengertian Bisnis}

Dataset yang digunakan telah disediakan oleh perusahaan supermarket yang merinci aktivitas penjualan supermarket. Dataset tersebut merupakan salah satu history penjualan perusahaan supermarket yang tercatat di 3 cabang berbeda selama 3 bulan. Penelitian ini fokus pada masalah bagaimana menemukan beberapa wawasan yang dapat membantu mereka meningkatkan strategi penjualan dan pemasaran. Terdapat beberapa pertanyaan diajukan untuk analisis data, yaitu

1. Pada bulan apa sebagian besar penjualan terjadi?

2. Bagaimana kinerja secara keseluruhan di kantor cabang? 


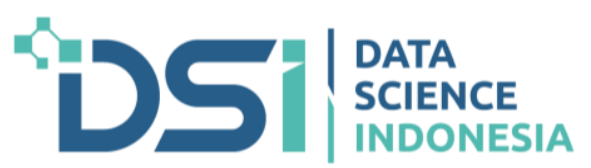

3. Berapa jumlah pelanggan yang menghasilkan lebih banyak pendapatan kotor? Dan apakah metode pembayaran memengaruhi pengalaman pelanggan sesuai jenis kelamin?

4. Produk dalam seminggu yang menghasilkan dan apa produk paling banyak terjual? Apakah penjualan produk ini menguntungkan?

5. Bagaimana peringkat lini produk yang berbeda? Apakah ada hubungan peringkat dengan harga?

6. Bagaimana pelanggan yang berbeda lebih suka mengunjungi supermarket?

\section{Analisis dan Pemahanan Data}

Berdasarkan ketiga pertanyaan tersebut, wawasan yang ingin dicapai adalah:

- Menemukan hubungan kolom yang paling berkorelasi

- Menemukan kota tersibuk, jenis pembayaran, cabang

- Memvisualisasikan perbandingan berbasis Gender untuk jenis produk yang berbeda

- Memvisualisasikan perbandingan berbasis Kota untuk jenis produk yang berbeda

- Menemukan metode pembayaran mana yang lebih sering digunakan di kota, cabang, dan untuk jenis produk tertentu

- Menemukan cabang mana yang memiliki penjualan lebih baik untuk produk mana.

\section{HASIL PENELITIAN}

Pada bagian ini diuraiakn hasil penelitian dimana aplikasi dibangun menggunakan bahasa pemrograman python 3 dengan jupyter notebook, beberapa pustaka seperti numpy, pandas, seaborn dan matplotlib digunakan dalam pengolahan data, visualisasi dan normalisasi data. Hasil yang ditampilkan pada bagian ini merupakan uraian jawaban beberapa pertanyaan yang diajukan dalam analisis bisnis.

1. Pada bulan apa sebagian besar penjualan terjadi?
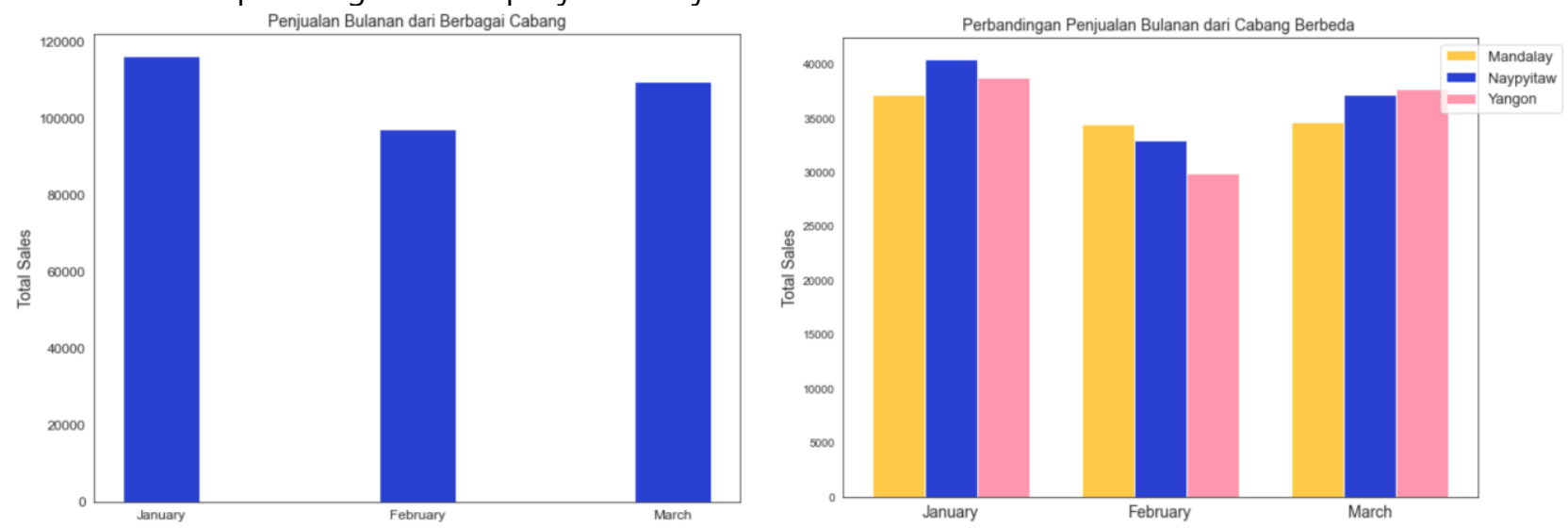

Gambar 1 Analisis Penjualan Bulanan berbagai cabang

Dari Januari, penjualan supermarket sedikit menurun dan bulan februari menerima penjualan paling sedikit. Hal ini bisa jadi karena Februari adalah bulan terpendek, namun perubahan penjualan per bulan tidak terlalu signifikan dan transaksi penjualan setiap cabang serupa dan cabang di kota Mandalay merupakan penjualan paling konsisten diantara cabang lain.

2. Bagaimana kinerja secara keseluruhan di kantor cabang? 

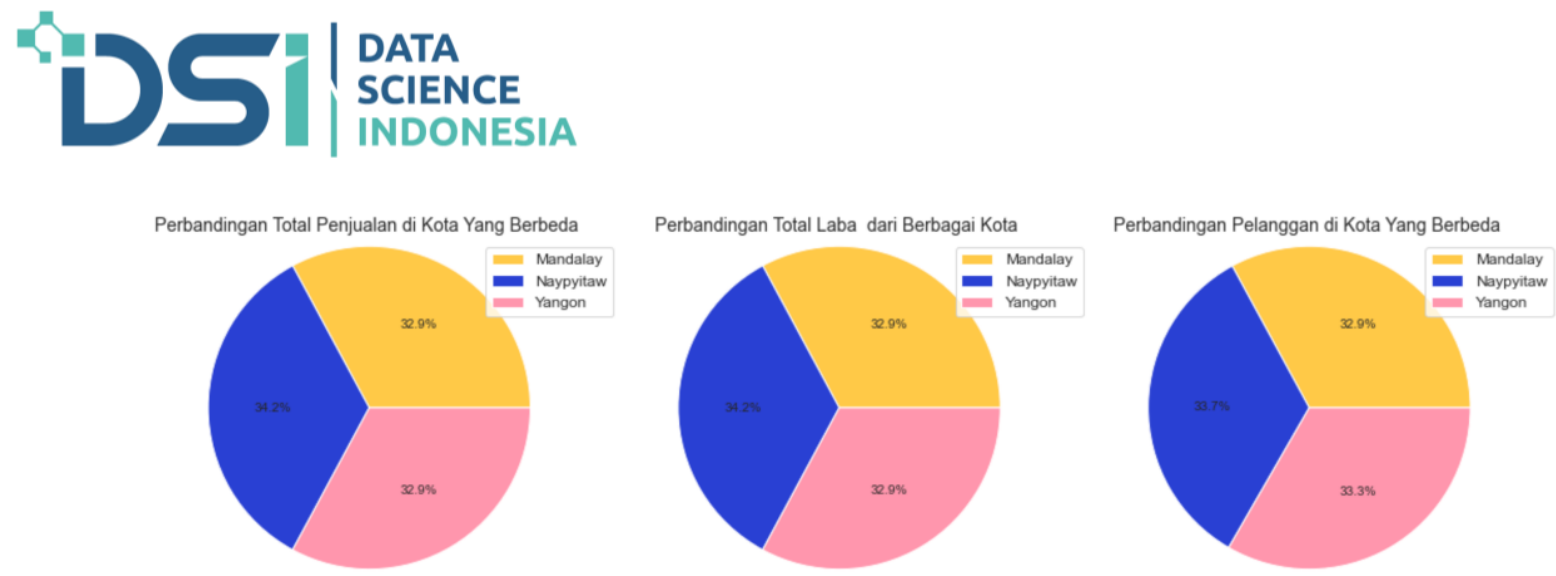

Gambar 2 Perbandingan kinerja cabang

Dari hasil grafik pada gambar 2 penjualan dan keuntungan Napyitaw sedikit lebih besar dengan anggota yang hampir sama di setiap cabang.

3. Berapa jumlah pelanggan yang menghasilkan lebih banyak pendapatan kotor? Dan apakah metode pembayaran memengaruhi pengalaman pelanggan sesuai jenis kelamin?
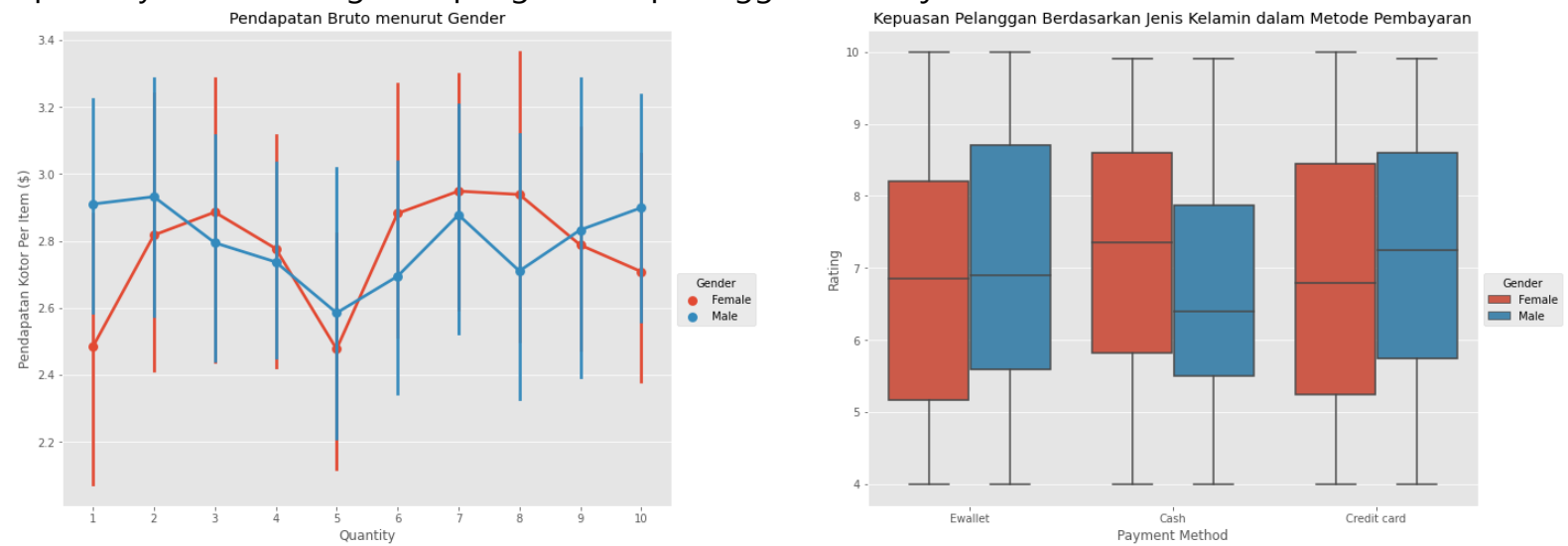

Gambar 3 Pendapatan dan Kepuasan pelanggan

Grafik menunjukkan bahwa pelanggan pria menghasilkan lebih banyak pendapatan kotor per item saat membeli item dengan jumlah yang lebih rendah. Di sisi lain, pelanggan wanita cenderung menghasilkan lebih banyak pendapatan kotor per item saat membeli dalam jumlah yang lebih tinggi. Grafik Kepuasan metode pembayaran menunjukkan bahwa pelanggan pria cenderung memberikan peringkat kepuasan yang lebih tinggi untuk pengalaman berbelanja saat mereka membayar menggunakan e-wallet atau kartu kredit. Pelanggan wanita, sebaliknya, cenderung memberikan peringkat kepuasan yang lebih tinggi untuk pengalaman berbelanja saat membayar tunai.

4. Produk dalam seminggu yang menghasilkan dan apa produk paling banyak terjual? Apakah penjualan produk ini menguntungkan?
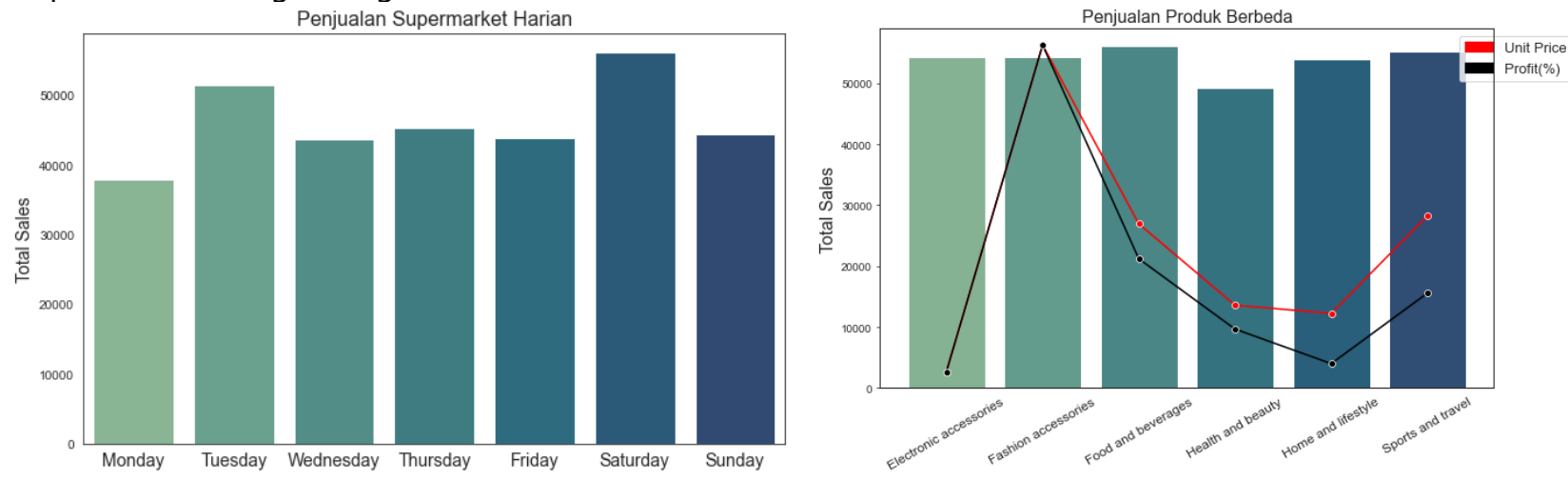

Gambar 4 Analisis Penjualan berdasarkan produk

Pada grafik penjualan supermarket harian dapat dilihat bahwa pada hari Selasa dan Sabtu memiliki penjualan yang lebih besar dalam seminggu dan hari Senin adalah hari dimana penjualan paling sedikit. Sementara tren 
penjualan produk yang berbeda menghasilkan penjualan yang tidak terjauh berbeda dimana keuntungan kirakira sebanding dengan harga dan untuk produk aksesoris fashion dan makanan dan minuman secara signifikan lebih besar.

5. Bagaimana peringkat produk yang berbeda? Apakah ada hubungan peringkat dengan harga? Memahami peringkat produk merupakan salah satu bagian penting yang perlu di analisis sehingga dapat menjadikan sebuah acuan dalam kampaye pemasaran, selain itu informasi ini sangat berguna agar tidak terjadi kekosongan ataupun kelebihan stok. Dari hasil grafik pada gambar 5 dapat dilihat bahwa produk dengan harga yang lebih kecil cenderung mendapatkan peringkat yang sedikit lebih rendah.

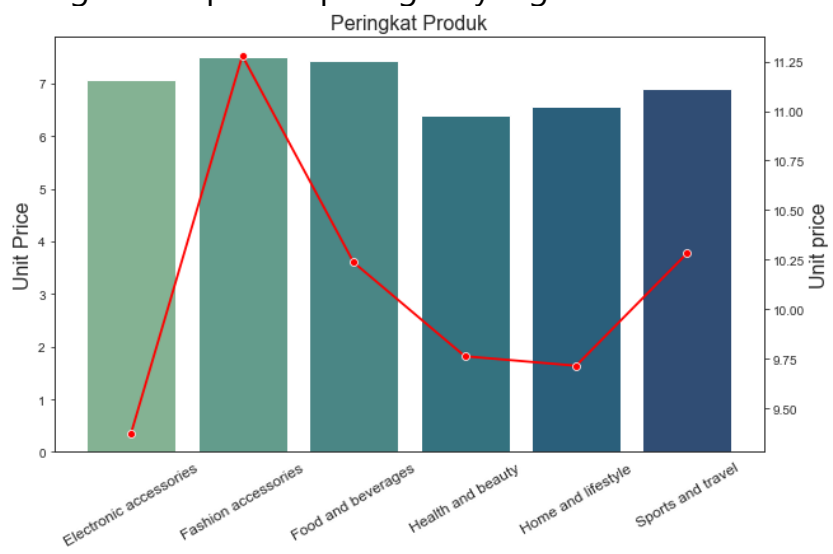

Gambar 5 Analisis Peringkat Produk

6. Bagaimana pelanggan yang berbeda lebih suka mengunjungi supermarket? Siapa pembeli utama?

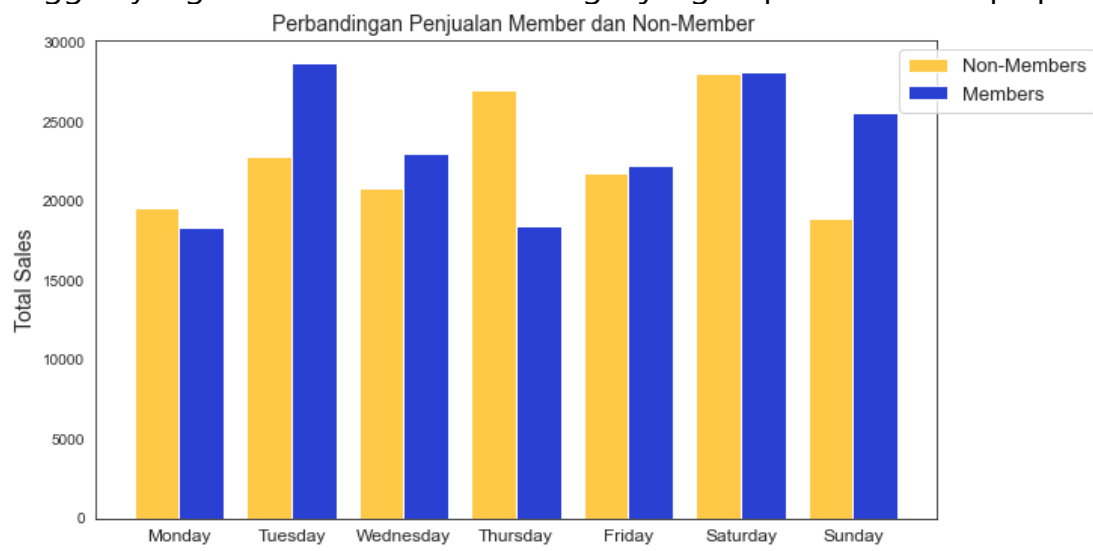

Gambar 6 Analisis Kunjungan Pelanggan berbeda

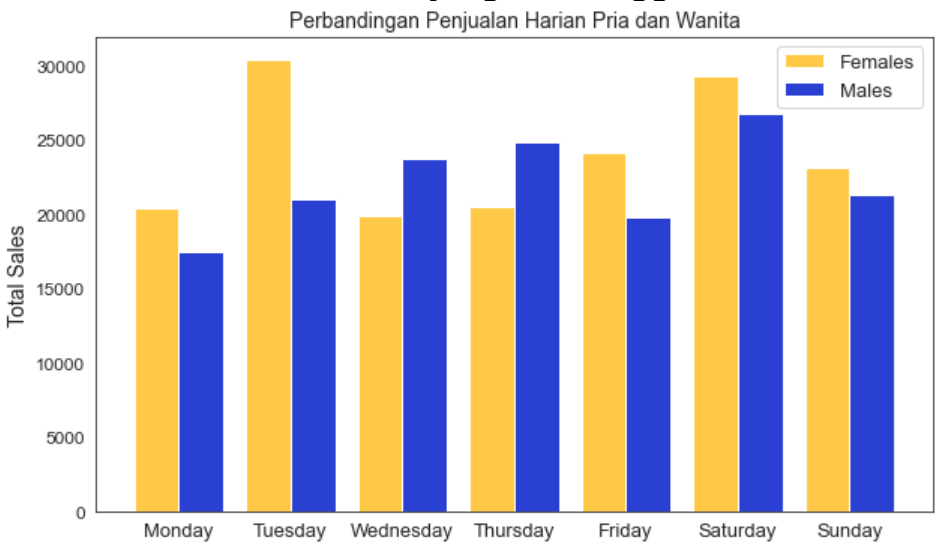

Gambar 7 Analisis Pembeli utama 
Pada gambar 6 dapat dilihat bahwa umumnya pelanggan melakukan kunjungan pada supermarket pada hari selasa dan minggu dan pembelian member lebih besar. Pada hari-hari ini, supermarket harus fokus pada segmen anggota. Pada hari Kamis, pembelian non-anggota lebih besar. Pada hari ini, supermarket memiliki peluang lebih besar untuk meningkatkan keanggotaan. Penjualan dari pria dan wanita serupa. Keluarga tampaknya melakukan sebagian besar pembelian, istimewanya, pada hari Selasa jumlah pelanggan wanita jauh lebih besar. Karena itu; pada hari selasa, supermarket harus lebih fokus pada segmen wanita. Sedangkan pada hari rabu dan kamis memiliki lebih banyak pelanggan pria. Karena itu; Pada hari-hari ini, supermarket harus fokus pada segmen pria.

\section{Diskusi}

Berdasarkan hasil analisis, maka temuan yang dapat berguna bagi perusahaan adalah kota yang dipilih untuk ekspansi di cabang Kota Naypyitaw dan kategori produk Makanan dan Minuman, Assesories Mode, dan Elektronik perlu dilakukan inventaris barang. Perusahaan harus meningkatkan pelayanan di ranah Elektronika dan layanan dalam mode pembayaran tunai. Kemudian total pelanggan 1000 terdiri dari wanita 501 dan pria 401 dengan rata-rata rating 6.9, rating terendah 4 dan tertinggi 10. Peringkat produk terbaik adalah makanan dan minuman dengan rata-rata pendapatan $\$ 307.58$, pendapatan bersih berada pada produk Rumah \& Gaya Hidup, pendapatan minimum produk Aksesoris Fashion dan umumnya pelanggan maksimum membeli 10 jenis produk dengan jenis pembayaran terbanyak melalui e-wallet. Umumnya wanita lebih dominan membeli produk Aksesoris Fashion dan pria Kesehatan \& Kecantikan.

\section{KESIMPULAN}

berdasarkan hasil analisis pada kumpulan data transaksi penjualan supermarket di 3 kota cabang, maka sangat perlu dipertimbangkan untuk meningkatkan pelayanan pada transaksi pembayaran tunai dan produk elektronik merupakan salah satu produk penjualan terendah di cabang kota Naypyitaw. Namun untuk produk Makanan dan Minuman, Assesories Mode, dan Elektronik perlu di inventarisasi agar tidak terjadi kekurangan stok.

\section{Supplementary Materials (optional)}

Tidak tersedia.

\section{Konstribusi Peneliti}

Semua penulis memiliki konstribusi yang sama pada makalah ini dan semua penulis telah membaca dan menyetujui versi manuskrip yang diterbitkan.

\section{Konflik kepentingan}

Para penulis menyatakan tidak ada konflik kepentingan.

\section{REFERENCES}

Anshari, Muhammad, Mohammad Nabil Almunawar, Syamimi Ariff Lim, and Abdullah Al-Mudimigh. 2019. "Customer Relationship Management and Big Data Enabled: Personalization \& Customization of Services." Applied Computing and Informatics 15(2):94-101. doi: 10.1016/j.aci.2018.05.004.

Bashir, Dr Rizwana, Irsa Mehboob, and Waqas Khaliq Bhatti. 2015. "Effects of Online Shopping Trends on Consumer-Buying Behaviour: An Empirical Study of Pakistan." Journal of Management and Research 2(2). Dhar, By Vasant. 2013. "Data Science and Prediction." Communications of the ACM 56(12):64-73.

Gull, Muqaddas, and Arshi Pervaiz. 2018. "Customer Behavior Analysis towards Online Shopping Using Data 
Mining." 5th International Multi-Topic ICT Conference: Technologies For Future Generations, IMTIC 2018 Proceedings 1-5. doi: 10.1109/IMTIC.2018.8467262.

Istiqomatin, Tutik, Agus Setiadi, and Titik Ekowati. 2021. "Effect of Marketing Mix on Consumer Purchase Decisions to Buy Cavendish Banana at Modern Markets in Semarang." Journal of Agricultural Socioeconomics and Business 4(2):120-32.

Jha, Narendra Kumar, Manoj Kumar, Anurag Kumar, and Vijay Kumar Gupta. 2014. "Customer Classification in Retail Marketing by Data Mining." International Journal of Scientific \& Engineering Research 5(4):1-8.

Lieder, Michael, Farazee M. A. Asif, and Amir Rashid. 2020. "A Choice Behavior Experiment with Circular Business Models Using Machine Learning and Simulation Modeling." Journal of Cleaner Production 258:120894. doi: 10.1016/j.jclepro.2020.120894.

Maheswari, K., P. Packia, and Amutha Priya. 2017. "Predicting Customer Behavior in Online Shopping Using SVM Classifier." IEEE INTERNATIONAL CONFERENCE ON INTELLIGENT TECHNIQUES IN CONTROL,OPTIMIZATION AND SIGNAL PROCESSING.

Peng, Roger D., Elizabeth Matsui, Roger D. Peng \& Elizabeth Matsui, Roger D. Peng, and Elizabeth Matsui. 2015. "The Art of Data Science: A Guide for Anyone Who Works with Data." Journal of Chemical Information and Modeling 53:159. doi: 10.1017/CBO9781107415324.004.

Rahim, Mussadiq Abdul, Muhammad Mushafiq, Salabat Khan, and Zulfiqar Ali Arain. 2021. "RFM-Based Repurchase Behavior for Customer Classification and Segmentation." Journal of Retailing and Consumer Services 61(April):102566. doi: 10.1016/j.jretconser.2021.102566.

Rita, Paulo, Tiago Oliveira, and Almira Farisa. 2019. "The Impact of E-Service Quality and Customer Satisfaction on Customer Behavior in Online Shopping." Heliyon 5(10):e02690. doi: 10.1016/j.heliyon.2019.e02690.

Salehinejad, Hojjat, and Shahryar Rahnamayan. 2017. "Customer Shopping Pattern Prediction: A Recurrent Neural Network Approach." 2016 IEEE Symposium Series on Computational Intelligence, SSCI 2016. doi: 10.1109/SSCI.2016.7849921.

Vijayakumar, V., and V. Neelanarayanan. 2016. Data Mining Approach for Intelligent Customer Behavior Analysis for a Retail Store. Vol. 49. edited by V. Vijayakumar and V. Neelanarayanan. Cham: Springer International Publishing.

Virkus, Sirje, and Emmanouel Garoufallou. 2019. "Data Science from a Library and Information Science Perspective." Data Technologies and Applications 53(4):422-41. doi: 10.1108/DTA-05-2019-0076.

Volk, Matthias, Abed Elrahman Shareef, Naoum Jamous, and Klaus Turowski. 2017. "New E-Commerce User Interest Patterns." Proceedings - 2017 IEEE 6th International Congress on Big Data, BigData Congress 2017 406-13. doi: 10.1109/BigDataCongress.2017.60. 